\title{
A Small Nudge can make a Difference: Impact of Passive Feedback on Prescription Behavior
}

\author{
${ }^{1}$ VK Tadia, ${ }^{2}$ R Ahlawat, ${ }^{3}$ SK Arya, ${ }^{4}$ DK Sharma
}

\begin{abstract}
It is generally believed that big changes can be brought about by big interventions. Sometimes, small interventions also can show spectacular results. This case describes the impact of simple intervention, audit and feedback on change in the behavior of clinicians. In this case, the impact of simple intervention in the form of passive feedback has been documented. All the prescriptions received in pharmacy during the period of study were scrutinized for specific prescription errors. An overall error rate of $0.12 \%$ was observed in phase 1 of the study, which was reduced to $0.04 \%$ during phase 2 of the study after implementation of the intervention, which further dropped to zero during phase 3 . It was concluded that a simple audit and feedback nudged the recipients of the feedback to modify their behavior.
\end{abstract}

Keywords: Audit, Feedback, Nudge, Passive feedback, Prescription behaviour.

How to cite this article: Tadia VK, Ahlawat R, Arya SK, Sharma DK. A Small Nudge can make a Difference: Impact of Passive Feedback on Prescription Behavior. Int J Res Foundation Hosp Health Adm 2016;4(1):31-34.

Source of support: Nil

Conflict of interest: None

\section{INTRODUCTION}

The All India Institute of Medical Sciences, New Delhi, runs an Employee's Health Service (EHS) scheme to provide medical/health facilities to all its employees and members on a contributory basis. The facilities admissible under the scheme are available to all central/state government employees on deputation and their families. All the beneficiaries under the scheme are issued with identity cum EHS card and are allotted an EHS number. This EHS number needs to be quoted on all papers and documents pertaining to medical care of the employees and their dependents.

Many prescriptions are received in the EHS pharmacy daily, sometimes with errors in a few of them. The EHS

\footnotetext{
${ }^{1}$ Resident Administrator, ${ }^{2}$ Senior Resident, ${ }^{3}$ Professor ${ }^{4}$ Medical Superintendent

${ }^{1-4}$ Department of Hospital Administration, All India Institute of Medical Sciences, New Delhi, India

Corresponding Author: VK Tadia, Resident Administrator Department of Hospital Administration, All India Institute of Medical Sciences, New Delhi, India, e-mail: vijay@vijaytadia.org
}

pharmacists had raised a complaint against this and had asked for a solution to this problem so that they could dispense the medicines at EHS counters without any confusion. Considering this problem, a meeting was held in which it was decided to quantify the problem and look for possible solutions. This study was undertaken at EHS pharmacy subsequent to the above developments. Further, it was decided that it should not merely be a faultfinding exercise, and the results of the audit would be shared with the in-charge Chief Medical Officer, EHS and its impact would be evaluated. All the stakeholders were involved as a team in this study. All of them participated with a sense of belonging and in the end, the results led to the mutual satisfaction of all the stakeholders.

During the course of study, it was found that the errors that generally occur could be clubbed into 6 groups, the details of which are provided later in the article. An informal feedback was shared after an audit of phase 1 findings. This feedback was well taken and appreciated by the in-charge Chief Medical Officer, EHS. Motivated by this, the feedback of phase 2 was shared formally.

The audit and feedback process involves retrospective reporting of information to individuals or organizations about their actions. The information is collected from actual practice in order to increase insight into particular actions. Data can be collected through either internal audit, where clinicians are involved in data collection, or external audit where others collect and collate the information. The feedback can be on outcomes of care, costs, or other elements of clinical performance and it may be comparative among peers or noncomparative. ${ }^{1}$

\section{MATERIALS AND METHODS}

\section{Study Design}

A prospective interventional study was carried out to assess the impact of passive feedback on clinicians' behavior in health care settings.

\section{Study Period}

The study was conducted in three phases, i.e., phase 1 (preintervention) and phase 2 (postintervention) and phase 3 (follow up). In phase 1, the study was carried out from October 28, 2015 to December 16, 2015 and the 
phase 2 of the study was carried out from December 28, 2015 to February 16, 2016. Both the phases of the study were of 50 days each. In between these two phases, the intervention was instituted. A follow-up study for another 50 days was undertaken from February 28, 2016 to April 17, 2016 to evaluate the number of errors observed after giving feedback of phase 2 to the Chief Medical Officer, EHS. The total duration of the study was 111 days.

\section{Intervention}

The intervention was conducted in the form of passive informational feedback, which was provided to the incharge Chief Medical Officer, EHS outpatient department (OPD) after auditing and analyzing the data obtained in phase 1 of the study.

\section{Data Collection}

Data was collected through pharmacists posted at EHS pharmacy. All the prescriptions in the mentioned duration were studied and errors were notified separately. The commonly occurring errors were classified under following heads and analyzed statistically:

- Number of times available drugs were prescribed under local purchase*

- Number of times wrong quantity was mentioned

- Number of times blank prescription was signed

- Number of times wrong drug/dose was prescribed

- Same drug was prescribed twice

- Doses were not mentioned

*When the drug prescribed or the substitute is not available in the pharmacy, the medicine is purchased through the hospital store and is issued to the patient through local purchase counter of the pharmacy. ${ }^{2}$

\section{RESULTS}

The present study was carried out at EHS pharmacy at the All India Institute of Medical Sciences, New Delhi. A total of 85,238 prescriptions were studied in three phases of the study. In phase 1, total 27,988 EHS patient prescriptions were studied, whereas in phase 2 , a total of 29,017 prescriptions were studied over a period of 50 days. On an average, 559 prescriptions were studied per day in phase 1 (preintervention) and 580 prescriptions were evaluated in phase 2 (postintervention) of the present study. The follow-up phase 3 included 28,233 EHS patient prescriptions.

\section{SUMMARY}

Phase 1 errors: $33 / 27,988=0.12 \%$

Phase 2 errors: $11 / 29,017=0.04 \%$

Phase 3 errors: $0 / 28,233=0 \%$
A total of 33 errors were identified in phase 1 of the study, which constitutes $0.12 \%$ of the total prescriptions studied in phase 1 (Table 1 ).

Maximum number of errors noticed were 15 (45.4\%), i.e., the number of times wrong quantity was mentioned, followed by $8(24.2 \%)$ prescriptions wherein drugs available in the hospital pharmacy were asked to be procured through local purchase. Least number of errors i.e., 1 (3\%), were noticed as "dosage not mentioned" and "same drug prescribed twice."

A total 11 of errors were identified in phase 2 of the study, which constitutes $0.04 \%$ of the total prescriptions studied in phase 2 (Table 2).

The maximum number of errors noticed in the postintervention period were $5(45.5 \%)$, i.e., number of times drugs available in the hospital pharmacy were asked to be procured through local purchase, whereas in $3(27.2 \%)$ wrong quantity was mentioned. No drug was prescribed twice in the postintervention period and no errors were made in prescribing appropriate dosage.

In follow-up phase 3, no errors were observed, which points to the fact that impact of the intervention was sustainable over a period of time.

The errors were significantly lower in phase 2 , with p-value of 0.001 (Table 3).

There was no significant difference in the frequency of the distribution of errors (Table 4).

Table 1: Frequency and type of errors identified in phase 1 of the study

\begin{tabular}{ll}
\hline Error & Phase 1 \\
\hline Number of times wrong quantity was mentioned & 15 \\
$\begin{array}{l}\text { Number of times available drugs were prescribed } \\
\text { under local purchase }\end{array}$ & 8 \\
$\begin{array}{l}\text { Number of times wrong drug/dose was prescribed } \\
\text { Number of times blank prescription/without }\end{array}$ & 5 \\
OPD card prescription was signed & 3 \\
Same drug was prescribed twice & 1 \\
Doses were not mentioned & 1 \\
\hline Total & 33 \\
\hline
\end{tabular}

Table 2: Frequency and type of errors identified in phase 2 of the study

\begin{tabular}{ll}
\hline Error & Phase 2 \\
\hline $\begin{array}{l}\text { Number of times available drugs were prescribed } \\
\text { under local purchase }\end{array}$ & 5 \\
Number of times wrong quantity was mentioned & 3 \\
Number of times wrong drug/dose was prescribed & 2 \\
$\begin{array}{l}\text { Number of times blank prescription/without OPD } \\
\text { card prescription was signed }\end{array}$ & 1 \\
Same drug was prescribed twice & 0 \\
Doses were not mentioned & 0 \\
\hline Total & 11 \\
\hline
\end{tabular}


Table 3: Chi-square test for comparison of the errors

\begin{tabular}{|c|c|c|c|c|c|}
\hline \multicolumn{6}{|c|}{ Error $\times$ phase cross-tabulation } \\
\hline & & & \multicolumn{2}{|c|}{ Phase } & \multirow[b]{2}{*}{ Total } \\
\hline & & & Phase 1 & Phase 2 & \\
\hline \multirow[t]{4}{*}{ Error } & \multirow{2}{*}{$\begin{array}{l}\text { Error } \\
\text { positive }\end{array}$} & Count & 33 & 11 & 44 \\
\hline & & $\%$ within phase & $0.1 \%$ & $0.0 \%$ & $0.1 \%$ \\
\hline & \multirow[t]{2}{*}{ No errors } & Count & 27,955 & 29,006 & 56,961 \\
\hline & & $\%$ within phase & $99.9 \%$ & $100.0 \%$ & $99.9 \%$ \\
\hline \multirow[t]{2}{*}{ Total } & & Count & 27,988 & 29,017 & 57,005 \\
\hline & & $\%$ within phase & $100.0 \%$ & $100.0 \%$ & $100.0 \%$ \\
\hline
\end{tabular}

Chi-square value 11.822 , $\mathrm{p}$-value 0.001

Table 4: Chi-square tests of the phase types of error difference

\begin{tabular}{|c|c|c|c|c|c|}
\hline \multicolumn{6}{|c|}{ Error $\times$ phase cross-tabulation } \\
\hline & & & \multicolumn{2}{|c|}{ Phase } & \multirow[b]{2}{*}{ Total } \\
\hline & & & Phase 1 & Phase 2 & \\
\hline \multirow[t]{12}{*}{ Error } & \multirow{2}{*}{$\begin{array}{l}\text { Doses not } \\
\text { mentioned }\end{array}$} & Count & 1 & 0 & 1 \\
\hline & & $\begin{array}{l}\% \text { within } \\
\text { phase }\end{array}$ & $3.0 \%$ & $0.0 \%$ & $2.3 \%$ \\
\hline & \multirow{2}{*}{$\begin{array}{l}\text { Number of times } \\
\text { available drugs } \\
\text { were prescribed } \\
\text { under local } \\
\text { purchase }\end{array}$} & Count & 8 & 5 & 13 \\
\hline & & $\begin{array}{l}\% \text { within } \\
\text { phase }\end{array}$ & $24.2 \%$ & $45.5 \%$ & $29.5 \%$ \\
\hline & \multirow{2}{*}{$\begin{array}{l}\text { Number of times } \\
\text { blank prescription/ } \\
\text { without OPD card } \\
\text { prescription was } \\
\text { signed }\end{array}$} & Count & 3 & 1 & 4 \\
\hline & & $\begin{array}{l}\% \text { within } \\
\text { phase }\end{array}$ & $9.1 \%$ & $9.1 \%$ & $9.1 \%$ \\
\hline & \multirow{2}{*}{$\begin{array}{l}\text { Number of times } \\
\text { wrong drug/dose } \\
\text { was prescribed }\end{array}$} & Count & 5 & 2 & 7 \\
\hline & & $\begin{array}{l}\% \text { within } \\
\text { phase }\end{array}$ & $15.2 \%$ & $18.2 \%$ & $15.9 \%$ \\
\hline & \multirow{2}{*}{$\begin{array}{l}\text { Number of times } \\
\text { wrong quantity } \\
\text { was mentioned }\end{array}$} & Count & 15 & 3 & 18 \\
\hline & & $\begin{array}{l}\% \text { within } \\
\text { phase }\end{array}$ & $45.5 \%$ & $27.3 \%$ & $40.9 \%$ \\
\hline & \multirow{2}{*}{$\begin{array}{l}\text { Same drug was } \\
\text { prescribed twice }\end{array}$} & Count & 1 & 0 & 1 \\
\hline & & $\begin{array}{l}\% \text { within } \\
\text { phase }\end{array}$ & $3.0 \%$ & $0.0 \%$ & $2.3 \%$ \\
\hline \multirow[t]{2}{*}{ Total } & & Count & 33 & 11 & 44 \\
\hline & & $\begin{array}{l}\% \text { within } \\
\text { phase }\end{array}$ & $100.0 \%$ & $100.0 \%$ & $100.0 \%$ \\
\hline
\end{tabular}

Fisher's exact test $3.108, p$-value 0.766

\section{DISCUSSION}

Errors in health care settings constitute a serious problem across the globe. It is generally noticed that junior doctors are likely to make more errors during their early medical practice.

The findings suggest that the errors were significantly lower in phase 2 of the study, i.e., from 0.12 to $0.04 \%$. There was a $66.6 \%$ reduction in the frequency of errors from phase 1 to phase 2 (Figure 1). The findings positively support that intervention had some impact and suggest that there has been a change in clinicians' behavior after provision of feedback. Further, no errors were observed during follow-up phase 3 , which points that the impact of the intervention was sustainable over a period of time. All the stakeholders were satisfied with the outcome in the end. This shows that even small interventions can sometimes lead to bigger results.

Further, the findings of the study suggest that audit and feedback are important tools to change the behavior of clinicians. Based on the findings, it was recommended that periodic audit and feedback should be given for better resource utilization, as well as better patient care services.

In a review paper published by Robertson and Jochelson, "Interventions that change clinician behaviour: Mapping the literature," different interventions have been mapped that can be used to change health professionals' behavior. This article suggests that audit and feedback are one of the modalities that can be used to modify the behavior of the clinicians in health care settings.

A Cochrane systematic review of audit and feedback studies found that there was no empirical basis for deciding how audit and feedback should be provided and recommends that the format should be based on pragmatic factors and local circumstances. ${ }^{4}$

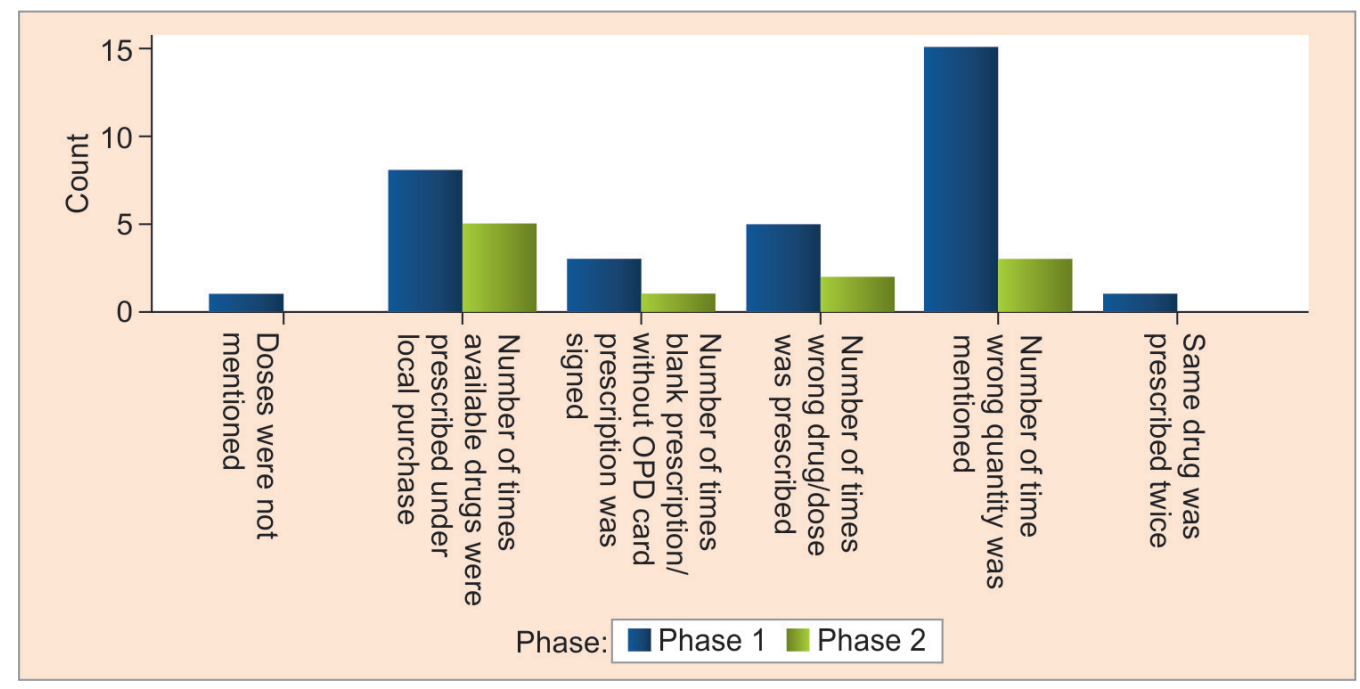

Fig. 1: Comparison of Errors in Phase 1 (Pre-Intervention) and Phase 2 (Post-Intervention) 
In spite of this, a number of reviews mention characteristics that have an impact on the effectiveness of feedback interventions. A review suggests that the effects of feedback might be larger if clinicians are actively involved, although lack of evidence makes this difficult to assess. ${ }^{4}$ Another review suggests that small group meetings with peers to discuss the data might increase the effectiveness of the audit, and that individual-level feedback may be more effective than that reported at group level. Feedback may be more effective if used in situations where individuals do not realize that their practice deviates from what is required. ${ }^{1}$

\section{REFERENCES}

1. Van der Weijden T, Grol R. Feedback and reminders. In: Grol R, Wensing $M$, Eccles $M$, editors. Improving patient care: the implementation of change in clinical practice. Edinburgh: Elsevier; 2005.

2. AIIMS Residents' Manual, 2005 Jul. p. 205-210. Accessed 2016 Jul 21. Available from: http://www.aiims.edu/images/pdf/ notice/syllabus-residents\%20manual.pdf.

3. Robertson R, Jochelson K. Interventions that change clinician behaviour: mapping the literature. 2006 Nov 27. p. 1-37.

4. Ivers N, Jamtvedt G, Flottorp S, Young JM, Odgaard-Jensen J, French SD, O'Brien MA, Johansen M, Grimshaw J, Oxman AD. Audit and feedback: effects on professional practice and health care outcomes. Cochrane Effective Practice and Organisation of Care Group; 2006. 